\section{Cyberpsychology: A Rapid Overview of Sexting}

\author{
Received: July 26, 2019; Accepted: August 25, 2019; Published: August 31, 2019
}

\section{Commentary}

Technology has revolutionized interpersonal relationships in many ways, including sexuality. Due to the interactivity that exists on the Internet and the accessibility of current devices, it is increasingly popular to experience sexuality through technology [1-3]. The term sexting came from the practice of sex or sexactivity related through text messages (texting) [4,5]. However, currently the practice of sexting is not limited to messages, since it can include videos, audios, photos, voice calls and video calls $[6,7]$. Young people are those who practice sexting the most and it has been related to the use of social networks $[8,9]$.

Some authors questioned sexting as a risk behavior, since it is usually a common practice for young people. However, it is considered a risk factor since, although it could be shared privately and a person of trust, the intimate material can reach third parties, either by intentional or unintentional dissemination, so there is a vulnerability of its privacy, exclusion, work/academic consequences, and intimidation, with consequences of feelings of guilt and shame, depression, among others, including suicide [4,10-13]. Although there are more studies regarding sexting, its research is still very limited. Several authors point out that more research is necessary to know the impacts and consequences, since it could be constituted as a risk behavior associated with different problems, such as risky sexual behaviors $[1,8]$. One of the main problems that has been found is that studies of sexting has focused on the consequences and not on the behavior itself. One of the factors that has greater relation is the cybernetic harassment, nevertheless some authors analyze them like a same concept, reason why it is important to analyze to the conduct and not in its possible consequences [9]. It is important to note that sexting is seen as a voluntary act while cyberbullying is something involuntary [8]. For example, it was found that depression is not related to sexting as consequence but it is related to cybervictimization [8]. Sexting is a risk factor for cybervictimization, since the intimate material can be used to blackmail the victim or cause damage through its diffusion $[2,9,14,15]$.

The relationship between risk behaviors in young people may be mediated by impulsivity. Impulsiveness has been related to sexting as well as other risk factors such as addictions and suicide [16-18]. Deepening on the explanations and consequences will be able to clarify the modern risk behaviors and it will be possible to deepen in its prevention and intervention $[6,19]$. Just as it can be treated as a popular and modern form of sexuality, mainly by young people, some studies relate it to negative aspects, and can be an

\section{Fuensanta Lopez-Rosales ${ }^{1}$, José Luis Jasso-Medrano ${ }^{2, *}$ and
Faustin Armel Etindele Sosso ${ }^{3,4,5}$

1 Innovation and Evaluation in Health Psychology, Psychology Faculty, Autonomous University of Nuevo Leon, Monterrey, Nuevo Leon, Mexico

2 Center for Research in Nutrition and Public Health, Autonomous University of Nuevo Leon, Monterrey, Nuevo Leon, Mexico

3 Centre for Advanced Studies in Sleep Medicine, Sacred Heart Hospital, Montreal, Canada

4 Institute of Health and Society, Faculty of Humanities, University of Quebec in Montreal, Canada

5 Quebec Network on Suicide, Mood Disorders and Related Disorders, Canada

\section{* Corresponding author: \\ Dr. José Luis Jasso-Medrano, \\ ” jose.jassomd@uanl.edu.mx}

\begin{abstract}
Center for Research in Nutrition and Public Health, Autonomous University of Nuevo Leon, Monterrey, Nuevo Leon, Mexico.
\end{abstract}

Tel: $+1-514-987-300$

Citation: Lopez-Rosales F, Jasso-Medrano JL, Sosso FAE (2019) Cyberpsychology: A Rapid Overview of Sexting. J Neurol Neurosci Vol.10 No.4:304

important risk factor. For this it will be important that the studies focus on the behavior and not on the consequences of sexting, since the virtual harassment and not the virtual sexuality practice would be really being investigated. Once the operationalization of sexting has been identified, it should be divided into its different types, as well as the frequency and with whom they regularly practice it, since there could be a difference between those who do it with their partner and those who practice it with strangers through of websites or social networks. Although quantitative 
research predominates in the subject, it will be important to prioritize a mixed research approach. That is, also include qualitative analyzes, which may be through interviews or focus groups, to determine and make more particular conclusions. So we can answer more questions, such as, Is every sexting practice a risk factor and is it related to negative aspects? Explore the

\section{References}

1 Leung L, Lee PS (2012) The influences of information literacy, internet addiction and parenting styles on internet risks. New Media \& Society 14: 117-136.

2 Benotsch EG, Snipes DJ, Martin AM, Bull SS (2013) Sexting, substance use, and sexual risk behavior in young adults. Journal of Adolescent Health 52: 307-313.

3 Gámez-Guadix M, Almendros C, Borrajo E, Calvete E (2015) Prevalence and association of sexting and online sexual victimization among spanish adults. Sexuality Research and Social Policy 12: 145-154.

4 Gordon-Messer D, Bauermeister JA, Grodzinski A, Zimmerman M (2013) Sexting among young adults. Journal of Adolescent Health 52: 301-306.

5 Döring N (2014) Consensual sexting among adolescents: Risk prevention through abstinence education or safer sexting. Cyberpsychology 8: 1-18.

6 Mercado Contreras CT, Pedraza Cabrera FJ, Martínez Martínez KI (2016) Sexting: Is definition, risk factors and consequences. Journal on Childhood and Adolescents 10: 1-18.

7 Klettke B, Hallford DJ, Mellor DJ (2014) Sexting prevalence and correlates: A systematic literature review. Clinical Psychology Review 34: 44-53.

8 Mitchell KJ, Finkelhor D, Jones LM, Wolak J (2012) Prevalence and characteristics of youth sexting: A national study. Pediatrics 129: 13-20.

9 Dake JA, Price JH, Maziarz L, Ward B (2012) Prevalence and correlates of sexting behavior in adolescents. American Journal of Sexuality Education 7: 1-15.

10 Jasso-Medrano JL, López-Rosales F, Gámez-Guadix M (2018) Assessing the links of sexting, cybervictimization, depression, and suicidal ideation among university students. Archives of Suicide Research 22: 153-164. behavioral mechanisms and neuropsychiatric outcomes related to addictive behavior, may help understanding the different risk factors involved in brain disorders [20-22]. Sexting is one subdivision of cyberpsychology and with the growing literature on the area, more epidemiological research in the future should be done to explain these mechanisms.

11 Ahern N, Mechling B (2013) Sexting: Serious problems for youth. Journal of Psychosocial Nursing and Mental Health Services 51: 22-30.

12 Fleschler M, Markham CM, Addy RC, Shegog R, Thiel M, et al. (2013) Prevalence and patterns of sexting among ethnic minority urban high school students. Cyberpsychology, Behavior and Social Networking 16: 454-459.

13 Hua L (2012) Technology and sexual risky behavior in adolescents. Adolescent Psychiatry 2: 221-228.

14 Korenis P, Billick SB (2014) Forensic implications: Adolescent sexting and cyberbullying. Psychiatric Quarterly 85: 97-101.

15 Reyns BW, Burek MW, Henson B, Fisher BS (2013) The unintended consequences of digital technology: Exploring the relationship between sexting and cybervictimization. Journal of Crime and Justice 36: 1-17.

16 Wolak J, Finkelhor D, Mitchell KJ, Ybarra ML (2010) Online "predators" and their victims. Psychology of Violence 1: 13-35.

17 Temple JR, Le VD, Van den Berg P, Ling Y, Paul JA, et al. (2014) Brief report: Teen sexting and psychosocial health. Journal of Adolescence 37: 33-36.

18 Gonzalez VM, Neander LL (2018) Impulsivity as a mediator in the relationship between problem solving and suicidal ideation. Journal of Clinical Psychology 74: 1626-1640.

19 Lee HW, Choi JS, Shin YC, Lee JY, Jung HY, et al. (2012) Impulsivity in internet addiction: A comparison with pathological gambling. Cyberpsychology, Behavior and Social Networking 15: 373-377.

20 Etindele Sosso FA, Molotchnikoff S (2016) Relation between cognitive impairment and the combined effects of environmental factors. Annual meeting on Depression, Anxiety and Stress Management 2016, Barcelona, Espagne, Spain.

21 Etindele Sosso FA (2018) Allostatic load or allostatic weight: A literature review of a confusing concept. J Neurol Neurosci 9: 242-247.

22 Raouafi S, Etindele Sosso FA (2017) Cyberpsychology: Video games as a perspective for cognitive training. Ment Health Addict Res 2: 1-2. 